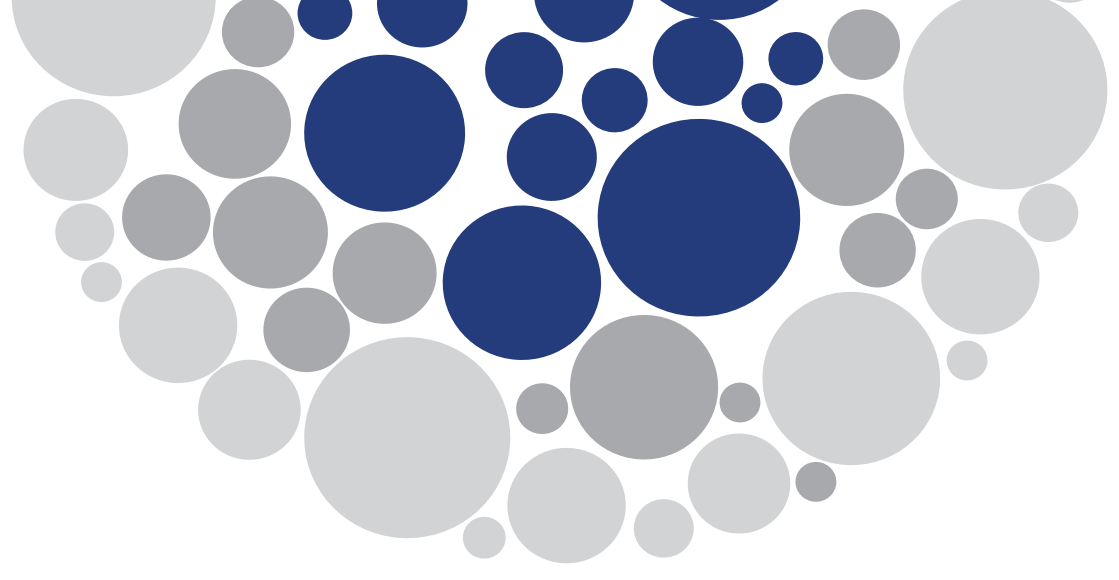

\title{
Escola Quilombola de Quissamã e bairros negros de Itaperuna: para pensar no racismo estrutural
}

\begin{abstract}
Felício Alves de Azeredo ${ }^{a}$, Marcia Aparecida Pereira de Mellob ${ }^{b}$ Edimilson Antônio Motac
a Universidade Federal Fluminense/Programa de Pós-Graduação em Geografia da UFF/CAMPOS. E-mail: felicioalves@id.uff.br b Universidade Federal Fluminense/Programa de Pós-Graduação em Geografia da UFF/CAMPOS. E-mail: marciamgg@gmail.com c PPG UFF Campos, Núcleo de Ensino e Pesquisa sobre Espaço e Currículo de Geografia e Imagem e Multiculturalismo NEPECGIM. E-mail: uffmota@gmail.com
\end{abstract}

A educação no Brasil se desenvolveu de forma elitista e excludente e, nos dias atuais, é gerida em todo o território nacional pelo Ministério da Educação (MEC), órgão responsável pelas políticas nacionais de educação de toda a rede de ensino pública e privada. A Educação Escolar Quilombola, garantida pela Resolução no 8/2012 (BRASIL, 2012), do Conselho Nacional de Educação (CNE), que definiu as Diretrizes Curriculares Nacionais para a Educação Escolar Quilombola na Educação Básica (DCNEEQ), é uma modalidade ofertada em escolas situadas em territórios quilombolas, com o objetivo de manter a cultura, os costumes e as tradições existentes dessa população no Brasil, o que facilitaria aos discentes uma aproximação com a história de seus ancestrais.

O sociólogo francês Pierre Félix Bourdieu (1996) afirma que lidar com a cultura na educação é um meio de nutrir o processo de aprendizagem dos discentes, levando-os à criticidade e ao sentimento de pertencimento ao meio em que estão inseridos. Bourdieu ainda diz que é impensável trabalhar a educação dissociada da cultura. Assim, as questões étnico-raciais, quando trabalhadas no processo de ensino e aprendizagem possibilitam combater o racismo estrutural e fomentam a educação antirracista.

Comumente nos deparamos com atos racistas no cotidiano ou com fatos veiculados pelas mídias a esse respeito. Conforme afirma a filósofa Djamila Ribeiro (2017), o 
racismo pode ser entendido como um "sistema de opressão que nega direitos, e não um simples ato da vontade do indivíduo", por isso a necessidade de trabalhar e entender o racismo em prol de transformar a sociedade brasileira em uma nação antirracista, ou seja, não apenas que não pratique o racismo, mas que combata sua prática, algo tão necessário hoje.

No Brasil, o sistema hegemônico de poder lida com os assuntos relacionados à população negra de forma resolvida ou romantizada pelo mito da democracia racial. Muitas vezes, as práticas sistemáticas racistas são reforçadas e enfatizadas, por exemplo, nos livros didáticos e recortes com tratamento da naturalização da miscigenação do período colonial, esvaziado de uma crítica a esse contexto histórico. Essa forma hegemônica de reprodução das narrativas raciais, geralmente, cria uma falsa harmonia racial no Brasil. Quando ela é confrontada com pesquisas e dados sobre o mapa racial brasileiro, os indicadores sociais e econômicos mostram que a situação do negro no país é o oposto do que tentam afirmar: que a situação do negro no Brasil não é inferior à do branco (ANJOS, 2005).

Reforçando o entendimento do racismo no Brasil, Munanga (2009) afirma que o racismo brasileiro se diferencia de outras partes do globo pelo fato de não ser explícito em todo o território nacional, mas silencioso. Sendo assim, é preciso romper com o silêncio estabelecido, com a harmonia que não existe, com o mito da democracia racial e com a redução do ser negro a determinados estereótipos.

Ribeiro (2017) diz que o silêncio é cúmplice da violência, por isso negros e brancos precisam se incomodar com a estrutura racista. É preciso questionar as pequenas questões vivenciadas no cotidiano que põem o negro como um ser reduzido na sociedade; é preciso enxergar o ser negro em toda a sua complexidade; é preciso entender que o racismo está em constante manutenção na sociedade, acompanhando todas as modificações que ocorrem nas relações sociais. Sobre esse assunto, o advogado, filósofo e professor Silvio Luiz de Almeida aponta que:

O racismo é parte da estrutura social e, portanto, não necessita de intenção para se manifestar, por mais que calar-se diante do racismo não faça do indivíduo moral e/ou juridicamente culpado ou responsável, certamente o silêncio o torna ética e politicamente responsável pela manutenção do racismo. (ALMEIDA, 2019, p. 34).

O autor ainda ressalta que, para mudar a sociedade, não basta apenas repudiar o racismo ou denunciar uma prática racista, mas "depende, antes de tudo, da tomada de postura e adoção de práticas antirracistas” (ALMEIDA, 2019, p. 32).

Sendo assim, engana-se quem pensa que o racismo é um assunto que deva ser discutido apenas pela população negra. Ele deve estar em pauta, principalmente, nas discussões daqueles que o praticam e o perpetuam na sociedade. Pensar que o fato de ter um amigo negro ou trabalhar com um preto isenta o indivíduo de ser racista é uma falácia. Tais afirmações só ajudam a fortalecer o racismo velado que existe na nossa sociedade, ampliando e fortalecendo as brincadeiras e piadas de cunho racista que estão presentes em nosso cotidiano.

Romper com a cultura do silêncio racial é se incomodar com o que está estabelecido, estranhar o comum e se indagar por que há tão poucos negros nas esferas de poder, na medicina, no corpo docente das universidades, chefes ou gerentes de empresas, já que no Brasil mais da metade da população é negra. Outra forma que pode contribuir para o 
rompimento desse silêncio é trabalhar nas discussões escolares indicadores que mostrem a situação da população negra, abordar questões como racismo recreativo e ressaltar a importância dessa população no processo da formação sociocultural do país.

\section{Educação Quilombola e implicações raciais}

Ao realizar-se uma análise histórica acerca das políticas educacionais brasileiras, percebe-se que ao negro sempre foi negado o direito de estudar. Por exemplo, a primeira lei referente à educação no Brasil, de 1837, afirmava a proibição dos escravizados e dos negros africanos, mesmo livres ou libertos, de estudarem. Essa proibição perdurou por um longo tempo, mesmo com o Decreto de $\mathrm{n}^{\circ}$ 7.031-A, de 6 de setembro de 1878, que autorizava o ensino da população negra no período noturno. Sabe-se que, mesmo com esse decreto, diversas manobras foram criadas para impedir o acesso à educação da população negra no Brasil.

As discussões acerca dessa temática se prolongaram durante anos no país, tendo maior visibilidade nos anos 1930, com a Frente Negra Brasileira, que lutou contra a estrutura racista vigente, levantando questionamentos quanto ao racismo e indagando o porquê da ausência dessa população em determinados cargos e posições na sociedade. Esses questionamentos foram aprimorados nos anos seguintes, tendo seu apogeu na institucionalização do Movimento Negro nos anos 1970 e 1980.

A Constituição de 1988, que assegura os direitos e deveres da população brasileira, afirma que a educação é um direito para todos os brasileiros do território nacional. O governo federal também garante saúde, cultura e educação aos descendentes quilombolas, por isso, nesse sentido, criou o programa Educação Escolar Quilombola, que tem como objetivo garantir a cultura e história da população quilombola do Brasil. Para isso, foi necessário criar diretrizes curriculares visando atender às especificidades dos alunos quilombolas.

Ainda nessa temática, vale ressaltar a Lei no $10.639^{1}$, de 9 de janeiro de 2003 (Brasil, 2003a), que alterou a Lei no 9.394/1996, tornando obrigatório o ensino da História e Cultura Afro-Brasileira nos estabelecimentos de Ensino Fundamental e Médio, oficiais e particulares. Essa lei representou uma forma de combater o racismo no Brasil pela educação, já que a escola é também um lugar de reprodução do racismo estrutural. Para fortalecer a luta da população negra brasileira, foi criado o Programa Brasil Quilombola, em 12 de março de 2004, que deu origem à Agenda Social Quilombola, por meio do Decreto $\mathrm{n}^{\circ} 6.261$, de 20 de novembro de $2007^{2}$, que possibilitou levantar questões quanto à educação e ao acesso à terra para os remanescentes de quilombos.

Visando avançar nas políticas e programas quilombolas, no ano de 2012 o MEC homologou a Resolução n 8/2012, que definiu as DCNEEQ. Essa conquista foi de muita importância, pois essas diretrizes possibilitaram o direcionamento da uma educação para os remanescentes de quilombos, para pensar nas questões culturais da comunidade e valorizá-las, considerando as especificidades do processo de ensino e aprendizagem da população quilombola.

1 Altera a Lei no 9.394, de 20 de dezembro de 1996, que estabelece as diretrizes e bases da educação nacional, para incluir no currículo oficial da rede de ensino a obrigatoriedade da temática "História e Cultura Afro-Brasileira", e dá outras providências (BRASIL, 2003).

2 Dispõe sobre a gestão integrada para o desenvolvimento da Agenda Social Quilombola no âmbito do Programa Brasil Quilombola, e dá outras providências (BRASIL, 2007). 
Sabe-se que, mesmo com todas essas conquistas, trabalhar as questões raciais na educação quilombola ainda é um desafio, pois, em diversos momentos, percebe-se pelos discursos da mídia ou até mesmo do setor político que esse assunto não é prioridade sem contar os atuais episódios ocorridos em órgãos públicos que tratam dessas questões no país, além dos investimentos que nem sempre chegam à ponta do processo, que são os alunos quilombolas. Para adicionar um agravante maior, o Estado extinguiu a Secretaria de Políticas de Promoção da Igualdade Racial (SEPPIR) ${ }^{3}$.

Os ataques começaram quando, no final do ano de 2018, o atual representante de Estado pensou na possibilidade de extinguir a SEPPIR, ocasionando diversos protestos e questionamentos acerca dessa decisão. Atualmente, a SEPPIR está inserida na pasta do Ministério da Mulher, da Família e dos Direitos Humanos. Com essa medida, percebe-se que, hoje, trabalhar as questões étnico-raciais no país se torna mais difícil com o atual governo, que lida com descaso quanto às políticas afirmativas.

Os episódios contra as instituições responsáveis pelas questões étnico-raciais se prolongaram. No ano seguinte, o Instituto Nacional de Colonização e Reforma Agrária (INCRA $)^{4}$, responsável pela delimitação e titulação das terras dos remanescentes de quilombos, ficou suspenso por alguns dias. Sem uma resposta clara sobre o ocorrido, a instituição retornou às atividades, mas há diversas reclamações quanto à atuação na titulação das terras pelas comunidades.

Esses acontecimentos vão ao encontro do apontamento de Silvio Luiz de Almeida (2019), no livro Racismo Estrutural, que afirma que o racismo se integra nas organizações econômicas, políticas e da sociedade. Quando o atual presidente da Fundação Cultural Palmares $(\mathrm{FCP})^{5}$ ataca diversos líderes de representatividade negra do país e tem um discurso que põe em questionamento as lutas dos povos negros no Brasil, ele reforça como é precisa a afirmação de Almeida (2019), levando-nos a perceber que o mito da democracia racial afeta toda a população, mesmo que de forma diferente, ou seja, alcança todos os indivíduos, independentemente do pertencimento étnico-racial. Uma forma de combater esse mito é trabalhar questões relacionadas aos negros no processo de ensino e aprendizagem, apresentando aos alunos as disparidades sociais e econômicas existentes no país quanto a essa população e proporcionar um currículo que resgate a história e a cultura afro-brasileira e africana, como se propõe a Escola Felizarda Maria Conceição de Azevedo.

\footnotetext{
${ }^{3}$ Fundada em 21 de março de 2003, a secretaria nasceu do reconhecimento das lutas históricas do Movimento Negro brasileiro. A data é emblemática, pois, em todo o mundo, celebra-se o Dia Internacional pela Eliminação da Discriminação Racial, instituído pela Organização das Nações Unidas (ONU), em memória do massacre de Sharpeville (BRASIL, 2003b).

${ }^{4}$ Por força do Decreto $n^{\circ}$ 4.887/2003, o INCRA é a autarquia competente, na esfera federal, pela titulação dos territórios quilombolas. As terras ocupadas por remanescentes das comunidades dos quilombos são aquelas utilizadas para a garantia de sua reprodução física, social, econômica e cultural. Como parte de uma reparação histórica, a política de regularização fundiária de territórios quilombolas é de suma importância para a dignidade e garantia da continuidade desses grupos étnicos (INCRA, 2020).

${ }^{5}$ No dia 22 de agosto de 1988, o governo federal fundou a primeira instituição pública voltada para promoção e preservação dos valores culturais, históricos, sociais e econômicos decorrentes da influência negra na formação da sociedade brasileira: a Fundação Cultural Palmares (FCP), entidade vinculada ao Ministério da Cidadania. Ao longo dos anos, a FCP tem trabalhado para promover uma política cultural igualitária e inclusiva, que contribua para a valorização da história e das manifestações culturais e artísticas negras brasileiras como patrimônios nacionais (BRASIL, 2017).
} 


\section{A Escola Quilombola Felizarda Maria Conceição de Azevedo em Quissamã}

O que distingue uma escola quilombola das demais é o fato de ela receber recursos do Programa Brasil Quilombola, do governo federal. Geralmente, está situada em territórios quilombolas ou em zonas rurais e oferta os conteúdos regulares, ou seja, conteúdos aplicados em todas as escolas do território brasileiro, porém destaca-se por um maior aprofundamento das questões raciais, da identidade negra e da interação entre a cultura e a história brasileira e africana.

A presente pesquisa sobre a educação quilombola foi realizada na Escola Municipal Felizarda Maria Conceição de Azevedo, inaugurada no dia 16 de maio de 2008, que se encontra situada na Estrada Principal Fazenda Machadinha, Bairro Fazenda Machadinha, Quissamã-RJ. A unidade oferta a Educação Infantil e o Ensino Fundamental I em período integral. O nome recebido por ela é em homenagem a Felizarda Maria Conceição de Azevedo, nascida em 19 de abril de 1884, filha da escrava Maria Januária da Conceição e do Visconde de Ururaí, Manuel Carneiro da Silva, senhor do Solar de Machadinha e genro do Duque de Caxias (MACHADO, 2006). Conhecida por muitos da cidade Quissamã, ela, sempre que solicitada por pesquisadores para conhecer a história local, estava disponível para contar suas experiências. Seu filho, Mário Azevedo, e algumas outras iniciativas culturais em Quissamã procuram resgatar e manter sua memória.

Em uma conversa com o diretor da instituição, foi possível perceber os desafios existentes em uma escola quilombola. O diretor afirmou que, de todos os problemas enfrentados, o obstáculo inicial foi inserir nas atividades escolares elementos que aproximassem a cultura afro-brasileira da comunidade. Relatou ainda como foi desafiador trabalhar com os docentes a importância de se elaborar atividades que abordassem elementos pertencentes aos ancestrais e também que levassem à formação cultural da comunidade Machadinha.

Segundo o diretor Daniel ${ }^{6}$, a direção, buscando solucionar essa situação, passou a desenvolver com os professores atividades relacionadas às questões étnico-raciais, como palestras, encontros e estudos sobre a Machadinha. A instituição passou a desenvolver projetos anuais que resgatassem a identidade negra presente na comunidade e, em 2019, criou uma série de encontros pedagógicos quinzenais para discutir um projeto político-pedagógico (PPP) que atendesse às Diretrizes Curriculares Quilombolas.

A escola conta com a participação de representantes da comunidade para relatar como é a realidade da Machadinha e busca atender às políticas estabelecidas no CNE de 2012 sobre as questões quilombolas, fazendo com que o PPP atinja todos os elementos exigidos pelas DCNEEQ.

Dessas atividades desenvolvidas na escola estão: Projeto Pequeno Griôs; Poesia em Ação (os alunos vão até a senzala recitar poemas); Dia de Celebrar as Conquistas (relacionado ao dia 13 de maio); dramatização valorizando a culinária local, representada pelos alunos da Educação Infantil; construção de maquetes com personagens negros; dança valorizando o jongo; e outras atividades artísticas e teatrais.

Dos treze professores da Escola Municipal Felizarda Maria Conceição de Azevedo, $69,23 \%$ trabalhavam nas atividades pedagógicas sobre a ancestralidade afro-brasileira, objetivando aproximar o aluno de sua história e da comunidade Machadinha. Segundo

\footnotetext{
${ }^{6} \mathrm{O}$ nome do diretor foi trocado para um fictício para preservar a identidade do entrevistado.
} 
os relatos docentes, houve um desafio para abordar a temática "étnico-racial" na prática pedagógica, pois alguns deles não tiveram uma formação nessa área em seus estudos. Este fato vai ao encontro do pensamento de Munanga (2005, p. 15), que afirma que muitos professores brasileiros "[...] não receberam [...] o necessário preparo para lidar com o desafio [da] problemática da convivência com a diversidade e as manifestações de discriminação dela resultadas".

É importante abordar a temática "educação das relações étnico-raciais" em todas as etapas de ensino, pois é preciso se colocar constantemente contra o racismo que perdura por séculos na sociedade brasileira e que está estruturado na educação. É necessário ressaltar as questões raciais na educação em todas as esferas, a começar pelos materiais didáticos, que, em sua maioria, retratam apenas o sofrimento da população negra, esquecendo sua importância para a formação sociocultural do Brasil. Sobre essas questões, Anjos (2005) pondera que a educação é ponto norteador e que por meio dela é possível modificar o quadro de atraso que há nos brasileiros no que diz respeito ao "[...] lugar insignificante a que os contextos afro-brasileiros têm sido relegados em quase todos os sistemas e níveis de ensino" (2005, p. 176). Do mesmo modo, pode-se evidenciar nas palavras do professor universitário, político e ativista dos direitos civis e humanos das populações negras, Abdias do Nascimento, que:

O sistema educacional [brasileiro] é usado como aparelhamento de controle nesta estrutura de discriminação cultural. Em todos os níveis do ensino brasileiro - elementar, secundário, universitário - o elenco das matérias ensinadas [...] constitui um ritual da formalidade e da ostentação da Europa. [...] Se consciência é memória e futuro, onde está a memória africana, parte inalienável da consciência brasileira? Onde e quando a história da África, o desenvolvimento de suas culturas e civilizações, as características do seu povo, foram ou são ensinadas nas escolas brasileiras? Quando há alguma referência ao africano ou negro, é no sentido do afastamento e da alienação da identidade negra. Tampouco na universidade brasileira o mundo negro-africano tem acesso. (NASCIMENTO, 1978 apud SANTOS, 2005, p. 23).

A ausência de pessoas negras na esfera de poder do ensino causa para o aluno negro uma série de consequências negativas, já que a todo instante sua identidade é negada ou ignorada enquanto tema insurgente do currículo que se estende da Educação Básica ao Ensino Superior. Sobre a presença do negro no currículo, Cavalleiro (2005) destaca a falta de representatividade nos materiais escolares, e isso contribui para a permanência do racismo estrutural.

Enfim, a Escola Municipal Felizarda Maria Conceição de Azevedo, diante de todas essas questões e do atual cenário, procura resgatar a identidade quilombola e as tradições da comunidade Machadinha. A instituição busca, em suas atividades e projetos anuais, reconhecer as práticas culturais locais da comunidade Machadinha e levar aos jovens remanescentes discussões acerca das questões raciais e da história de seus ancestrais, as quais são importantes para manter a representatividade da cultura quilombola em seu território.

Acreditamos que a escola é um lugar de direito com possibilidade para resgatar a cultura afro-brasileira e a história africana e, assim, promover o reconhecimento do negro, pois, durante muito tempo, a sua existência enquanto sujeito de direito ficou no silenciamento - e direito aqui evoca pensar não somente na escola e seu currículo, mas também no lugar de morar na cidade, como mostra a seção seguinte. 


\section{Bairros Negros no contexto histórico-racial de Itaperuna}

A memória é um dispositivo cognitivo e social que faz lembrar as formas de existir e de significar os objetos e equipamentos de diferentes tempos e espaços da cidade. Em seu romance As Cidade Invisiveis, Ítalo Calvino diz que: "A memória é redundante: repete os símbolos para que a cidade comece a existir" (CALVINO, 1990, p. 23). De fato, a existência de uma cidade se dá pela memória visual, e o seu espaço urbano é visto pelo olhar de quem se coloca a dizer sobre ela a respeito de suas projeções pretéritas e futuras. Definimos aqui o espaço urbano como o espaço da cidade, com ruas, bairros, praças e diferentes tipos de equipamentos, como fábricas, bancos, igrejas, casas, e com estrutura social própria do sistema urbano (CASTELLS, 2020, p. 340).

Sobre o tipo de cidade, Corrêa (1989) diz que o espaço urbano de uma cidade capitalista é simultaneamente fragmentado e articulado, e toda cidade como forma do espaço urbano está dividida em áreas residenciais segregadas, o que faz refletir da sua paisagem uma complexa estrutura social de diferentes classes sociais. Já em um recorte mais específico do espaço urbano, para Cunha Júnior (2019) “[...] a cidade é composta de bairros onde vivem as pessoas e onde a diversidade humana se manifesta". O autor afirma também que: "Existe uma intencionalidade em não tratar as temáticas de interesse da população negra e as raízes dessa problemática precisam ser pensadas e discutidas" (CUNHA JÚNIOR, 2019 , p. 19). Para esse autor, é fundamental que, ao estudar o campo do conhecimento urbanístico, haja uma preocupação de se centralizar na importância da produção da cidade, principalmente para as habitações que representam um tipo de indicador de desigualdade social e têm consequências visíveis para a vida da população negra, o que é chamado por ele de racismo antinegro. Ele o define assim:

O racismo antinegro como ideologia é estrutural na formação histórica brasileira, pode ser lido na história da realidade, constatado na geografia e na forma urbana das cidades brasileiras e deveria ser um conceito de análise nas diversas ciências humanas brasileiras, no entanto ocorre o contrário, o contraditório, racismo estrutural antinegro é conceito rejeitado por boa parte das ciências humanas sob a fraca alegação de que devido à "miscigenação racial" não existe racismo nas relações sociais brasileiras. (CUNHA JÚNIOR, 2019, p. 16).

Contra a permanência do racismo estrutural antinegro posto pelo autor, Mota (2009) diz que a questão racial no Brasil sempre foi tema de consenso e controvérsia. Isso está na idealização e na condução da elite dirigente do Estado, pois, em suas instâncias do poder, a sua maioria são homens e mulheres brancas que sempre utilizaram os mecanismos de controle e os discursos institucionais e que, de seus lugares de poder, como a universidade, a escola e a mídia, "[...] promoveram simbolicamente a integração nacional sob o 'conto das três raças', em que, brancos, negros e índios forjaram a identidade nacional do Brasil mestiço e homogêneo racialmente" (MOTA, 2009, p. 15).

Nesse mesmo sentido, sobre esse lugar de poder de homens e mulheres hegemonicamente brancos autorizados como únicos produtores do conhecimento científico e de narrativas sobre a cidade e o seu espaço urbano, Cunha Júnior (2019) diz haver a invisibilização da população negra no pensamento urbanístico, porque isso tem a ver com a sua não inserção no espaço urbano. Segundo esse autor, ainda é recorrente, ao tratar da segregação do espaço urbano, condenar "apenas o mercado imobiliário, sendo acrítico sobre as responsabilidades das instituições públicas e das universidades” em relação ao tema, 
por se afugentarem da discussão do racismo estrutural - pauta esta ainda cara para o Brasil (Cunha Júnior, 2019, p. 17). O autor diz que trazer o racismo como questão para pensar no urbano é um grande esforço intelectual, pois isso requer romper com o estado de invisibilidade que recai na população negra sob o peso da raça - raça aqui não no sentido biológico, porque não existe, mas como poder de estratificação social pela qual se reproduz estruturalmente a pecha do lugar invisível do negro sobre o seu passado histórico no espaço urbano.

Resgatar a produção dos bairros negros e periféricos de Itaperuna exige se debruçar sobre a sua paisagem e identificar os diferentes processos históricos que marcaram o espaço urbano iniciado no período colonial, como em tantas outras cidades brasileiras. O que define o bairro negro é o seu tempo-espaço de concentração populacional de maioria negra e de histórico de ancestralidade afrodescendente.

Itaperuna, como lugar de passagem entre Rio de Janeiro e as províncias de Minas Gerais, desde o início se despontou com uma economia agrária que se destacava no Norte Fluminense. O curso do rio Muriaé servia para marcar a rota de diferentes tropeiros, que se aventuravam em meio à mata virgem densa para povoar as terras e transportar mercadorias, entre as quais o escravizado africano reconhecido como não humano pelo sistema colonial.

No ano de 1834, o então colonizador José de Lannes Dantas Brandão fixou residência na região, onde demarcou o território da fazenda batizada como Porto Alegre, a qual possuía grande dimensão territorial. As dependências dela contavam com boa infraestrutura, comum a uma casa-grande do seu tempo. Porém, no mesmo ano, ele vendeu a propriedade ao sr. Abreu de Lima.

Documentos comprovam que o marco inicial de Itaperuna é a fazenda Porto Alegre. No decorrer do tempo, ela passou por diversos proprietários, até que, com a morte de seu último dono, o sr. Ábido Bussade, que veio a falecer em 1972, e depois de alguns anos sem função, as dependências foram refuncionalizadas para a casa de repouso para deficientes mentais (PIRES et al., 2005, p. 71).

Como toda casa-grande de uma produção colonial, a fazenda Porto Alegre possuía grande extensão de terras, com variação da cultura de subsistência e plantação.

A localização geográfica do sítio do entorno da fazenda Porto Alegre contribuiu para a rápida expansão urbana, e a vila foi elevada à categoria de cidade em 06 de dezembro de 1889, por meio Lei $n^{\circ} 2.921$, e recebeu o nome de Itaperuna, que, em Tupi- Guarani, significa "Caminho da Pedra Preta". Itaperuna em 6 de dezembro de 1889, quando deixou de ser vila e recebeu o título de cidade, contava sob sua jurisdição os seguintes distritos: São José do Avaí (Itaperuna), Nossa Senhora da Penha (Aré), Laje do Muriaé, São Sebastião da Boa Vista, Natividade do Carangola, Santo Antônio de Carangola (Porciúncula), Varre-Sai, Santa Clara de Carangola, Arrozal de Sant'Ana do Itabapoana (Rosal), Bom Jesus do Itabapoana, Santo Antônio do Itabapoana (Calheiros) e Santa Rita do Ouro Fino (DINIZ, 1985).

Com a abolição e o advento da República, consequentemente ocorreu o desenvolvimento urbano da cidade de Itaperuna, e a fazenda, que estava no centro do processo de expansão do seu entorno, passou para a especulação imobiliária. Desde então, muitos empreendimentos de capital privado foram construídos no entorno da antiga fazenda Porto Alegre. Atualmente, onde antes funcionava a sede da fazenda, encontram-se o clube $\mathrm{AABB}$, algumas residências particulares e comércios. Já onde eram as dependências da 
fazenda, como os terreiros para secar grãos, encontra-se a casa de festa "Espaço Lounge". Da paisagem antiga, o local preserva algumas palmeiras-imperiais e uma figueira-branca, cujo diâmetro mostra a resistência ao tempo físico e histórico - essa árvore é uma característica dos lugares onde os escravizados utilizavam como lugar de atividades laborais.

\section{Apontamentos para pensar no racismo em bairros periféricos de Itaperuna}

Estudar os bairros negros da cidade de Itaperuna impõe um desafio ao pesquisador, pois são praticamente inexistentes as fontes disponíveis. De acordo com Souza e Cunha Junior (2019), até então não houve esforço local para a preservação dos dados e tampouco pesquisas a esse respeito sobre a participação do negro na região de Natividade, que, anteriormente, pertencia ao município de Itaperuna.

Itaperuna cresceu seguindo às margens do rio Muriaé e serviu de orientação para os primeiros habitantes que chegavam e fixavam suas residências no entorno das suas margens. Quem tinha um poder aquisitivo melhor estabelecia residência mais perto do rio, buscando um melhor conforto; já os mais pobres ocupavam os lugares mais afastados. Essa dinâmica inicial pela ocupação do espaço urbano já mostra a sua segregação (SOUZA, 2018, p. 59). A elite local é o agente transformador e também segregador do espaço urbano da cidade de Itaperuna. Diferentemente dos pobres e da população negra deixada à margem da República pós-abolição, ela, na sua maioria, é detentora de posse e uso da terra e também que possui, primeiramente, acesso a bens e serviços dos quais a população pobre e negra não dispõe. Assim, a elite local é determinante na segregação econômica, porque os seus agentes são os detentores do meio de produção e os responsáveis pela reprodução do racismo estrutural, por ocuparem também os setores institucionais. São eles os (re)produtores dos discursos aceitos como únicos e legítimos, na manutenção do status quo das políticas sociais de habitação, saúde, educação e de assistência social e lazer.

Por outro lado, a cidade se desenvolveu graças às suas terras férteis, e seu relevo e sua hidrografia foram propícios para a cultura agrária, o que por muito tempo, durante $\mathrm{o}$ século XX, fez do Noroeste Fluminense uma região produtora de café.

Nesse contexto histórico e econômico, sabe-se que o crescimento de Itaperuna não foi planejado. Como muitas outras cidade no Brasil, ela cresceu atendendo às necessidades e demandas de bens e serviços dos grupos privilegiados e seguindo as regras postas pelo mercado imobiliário e pelas políticas de Estado, em detrimento dos grupos que historicamente sempre estiveram fora do lugar nas deliberações do espaço urbano (os pretos e pardos). É fato que os primeiros bairros na cidade se expandiram e se multiplicaram, gerando outros territórios, porém a divisão socioespacial-racial continua sendo o maior vetor de segregação.

A criação de cada um dos bairros itaperunenses remonta a história do começo da organização espacial da cidade, o que, para a sua compreensão, requer fazer um recorte de tempo-espaço e explicar as delimitações socioespaciais - atualmente, é possível ver os bairros com infraestrutura e valorização mobiliária elevada e os bairros com pouca infraestrutura e baixo valor mobiliário, chamados de periferia.

A saber, o bairro Centro teve início com a chegada dos colonizadores por volta de 1831 até aproximadamente 1881, quando ainda era Vila São José do Avaí. De acordo 
com Diniz (1985, p. 32), “A Vila São José do Avaí, pelas Leis provinciais no 2.810, de 24 de novembro de 1885, e 2.921, de 29 de dezembro de 1889, foi elevada à categoria de Município com a cidade Itaperuna". Herança da estrutura colonial racista, a expansão urbana de Itaperuna nasceu segregacionista, com aqueles que ficaram dentro e com os que ficaram fora. Próximo à linha férrea habitava a elite branca, e nos locais mais altos, nos morros, as pessoas pobres e negras - ainda hoje elas são encontradas nos mesmos lugares. Com o passar dos anos, o aumento populacional fez com que a zona central da cidade crescesse e se desmembrasse em novos bairros, como Morro do Castelo, Marca Tempo, Horto Florestal, Morro do Cristo e Bico da Foice. São bairros que foram agregando moradias com "ideias fora do lugar", porque esses lugares, segundo Cunha Júnior (2019, p. 21-22), “[...] não fazem parte do conhecimento universitário, em virtude da forma de construir não obedecer ao pretendido pelas formalidades teóricas, portanto desconsiderado e transformado em ilegal".

No caso do bairro Niterói, ele surgiu da demanda para alocar as famílias que chegavam ao município em busca de trabalho. Com o fim do período escravocrata e os libertos abandonados à própria sorte pelos seus ex-senhores, a migração para a cidade era a única certeza de novos horizontes. A perspectiva por novas oportunidades de trabalho era sua nova realidade. Pobres e pretos eram maioria na década de 1890 e migraram das fazendas da zona rural para a cidade, assumindo atividades econômicas, tais como: açougueiros, sapateiros, ferreiros, entre outros ofícios considerados autônomos. Portanto, o crescimento da cidade contou com a mão de obra do negro em diversos segmentos de serviços.

Hoje, a existência de muitos bairros negros em Itaperuna, como Morro do Castelo, Marca Tempo, Horto Florestal, Morro do Cristo e Bico da Foice - já citados anteriormente -, compostos, em sua maioria, por população preta e parda e com infraestrutura inferior aos bairros de classe média e média alta, nos quais a maioria da população é branca, demonstra uma definição racial de estratificação social de que esses bairros são ocupados e experenciados somente pela população negra. Negro aqui é raça, e raça é consciência do lugar de estratificação social que o negro ocupa por causa do racismo estrutural. Posto isso, para finalizar, é importante investigar, analisar e comparar a condição social vivida hoje pela população negra de Itaperuna. Portanto, essa é uma discussão que não se encerra neste breve trabalho, já que o tema "Bairros Negros de Itaperuna" faz parte de uma pesquisa que está em curso.

\section{Conclusão}

O presente texto abordou a implementação da Educação Escolar Quilombola na Escola Municipal Felizarda Maria Conceição de Azevedo, situada no território quilombola da comunidade Machadinha, no município de Quissamã, pertencente à região norte do estado do Rio de Janeiro. Buscou também entender os desafios e as possibilidades da prática e discurso docentes para se implementar um currículo com forma e conteúdo para a educação quilombola, considerando que a forma exige mudança de postura e pensamento para o combate ao racismo, conforme preconiza a Lei ${ }^{\circ} 10.639 / 2003$, e o conteúdo deve resgatar a cultural afro-brasileira e a história africana, o que envolve a prática pedagógica, bem como a ancestralidade dos quilombolas da Machadinha. 
Aqui ainda foi apresentado o contexto histórico-racial forjado na produção escravista, sendo a fazenda Porto Alegre o lugar onde o negro era desumanizado e escravizado pelo regime escravocrata. Foi a fazenda também o início do processo de urbanização da cidade de Itaperuna, o que fez com que o contingente escravizado deixasse de ocupar a senzala para ocupar as áreas distantes - hoje, a periferia da cidade, denominada bairros negros. O surgimento desses bairros negros em Itaperuna foi herança do racismo estrutural colonial, que passou a ser o lugar de morar do negro. Se, no primeiro momento, o negro era esvaziado da sua humanidade, agora, livre e homem, já na República, foi abandonado a um estado de invisibilidade, e, já se distanciando da casa-grande (fazenda Porto Alegre), o morro tornou o seu lugar de alcance. Nesse lugar ainda hoje se encontram os bairros negros de Itaperuna, os quais, quando comparados com os bairros de maioria branca, possuem menos infraestrutura e serviço público, como saúde, educação, assistência social e lazer.

Conclui-se que as temáticas apresentadas - o caso da Escola Municipal Felizarda Maria Conceição de Azevedo, que tratou das práticas e discursos docentes sobre a educação quilombola na escola em Quissamã, e o caso do resgate dos bairros negros de Itaperuna, que tem a origem histórica no escravização de africanos e afrodescendentes - têm em comum o objetivo de resgatar o tempo e o espaço, o passado e o presente do negro como sujeito da sua história e agente transformador do espaço social urbano. Nesse sentido, o resgate histórico da educação quilombola em Quissamã, na Machadinha, é uma possibilidade de ruptura com o silenciamento do estado de invisibilidade do negro na produção do conhecimento no contexto da educação brasileira, no campo do currículo, que, durante séculos, manteve a cultura afro-brasileira e a história africana interpretada por uma visão unicamente eurocentrista. Já quanto ao resgate dos bairros negros em Itaperuna, a proposta representa uma possibilidade de recontar a história da expansão urbana não mais por meio de uma visão branca, que por muito tempo silenciou a diferença entre pretos e brancos sob o mito da democracia racial. De fato, visto sob uma visão crítica, como aponta Nascimento (1978 apud SANTOS, 2005, p. 23), o sistema educacional é usado como aparelhamento de controle de discriminação da cultura afro-brasileira, sendo ainda hoje desafiador ao negro ocupar o seu lugar no currículo escolar e na universidade brasileira. Para Almeida (2019, p. 34), a diferença entre negro e branco se deve ao racismo estrutural antinegro. Para concluir, Cunha Júnior (2019) afirma que resgatar os bairros negros como tema de pesquisa é trazer para o debate o lugar do negro lugar até então fora das ideias urbanísticas, ou seja, do pensamento urbano enquanto campo das ciências humanas.

\section{REFERÊNCIAS}

ALMEIDA, S. L. Racismo estrutural. São Paulo: Pólen, 2019.

ANJOS, R. S. A. A África, a Educação Brasileira e a Geografia. In: BRASIL. Ministério da Educação. Secretaria de Educação Continuada, Alfabetização e Diversidade - SECAD. Educação anti-racista: caminhos abertos pela Lei Federal no 10.639/03. Brasília: Ministério da Educação, Secretaria de Educação Continuada, Alfabetização e Diversidade, 2005. (Coleção Educação para todos).

BOURDIEU, P. F. Razões práticas: sobre a teoria da ação. Campinas: Papirus, 1996.

BRASIL. Decreto de $n^{\circ}$ 6.261, de 20 de novembro de 2007. Dispõe sobre a gestão integrada para o desenvolvimento da Agenda Social Quilombola no âmbito do Programa Brasil Quilombola, e dá outras 
providências. Diário Oficial da República Federativa do Brasil, Brasília, DF, 2007. Disponível em: <http://www.planalto.gov.br/ccivil_03/_ato2007-2010/2007/decreto/d6261.htm>. Acesso em: 18 ago. 2020.

BRASIL. Resolução nº 8, de 20 de novembro de 2012. Define Diretrizes Curriculares Nacionais para a Educação Escolar Quilombola na Educação Básica. Diário Oficial da República Federativa do Brasil, Brasília, DF, 2012. Disponível em: $<$ http://portal.mec.gov.br/index.php?option=com_docman\&view=download\&alias=11963rceb008-12-pdf\&category_slug=novembro-2012-pdf\&Itemid=30192>. Acesso em: 27 ago. 2020.

BRASIL. Ministério da Justiça e Segurança Pública. Secretaria de Políticas de Promoção da Igualdade Racial - SEPPIR. Você conhece a SEPPIR. Brasília: Ministério da Justiça e Segurança Pública, 2017. Disponível em: <https://www.justica.gov.br/news/conheca-melhor-o-trabalho-da-seppir>. Acesso em: 18 ago. 2020.

CALVINO, Í. As cidades invisíveis. São Paulo: Companhia das Letras, 1990.

CASTELLS, M. A questão urbana. Rio de Janeiro: Paz \&Terra, 2020.

CAVALLEIRO, E. S. Introdução. In: BRASIL. Ministério da Educação. Secretaria de Educação Continuada, Alfabetização e Diversidade - SECAD. Educação anti-racista: caminhos abertos pela Lei Federal no 10.639/03. Brasília: Ministério da Educação, Secretaria de Educação Continuada, Alfabetização e Diversidade, 2005. (Coleção Educação para todos).

CORRÊA, R. L. O espaço urbano. São Paulo: Ática, 1989.

CUNHA JÚNIOR, H. Bairro negro, lugar fora das ideias urbanísticas. In: CUNHA JUNIOR, H. et al. (Org.). Bairros negros cidades negras. Fortaleza, CE: Editora Via Dourada, 2019.

DINIZ, D. O desenvolver de um município Itaperuna: do germinar à frutificação. Rio de Janeiro: Damadá, 1985.

INSTITUTO NACIONAL DE COLONIZAÇÃO E REFORMA AGRÁRIA - INCRA. Passo a passo titulação de territórios quilombolas. Brasília: INCRA, 2020. Disponível em: <http://www.incra.gov. br/pt/quilombolas.html>. Acesso em:18 ago. 2020.

MACHADO, F. S. Fazenda Machadinha: memória e tradições culturais em uma comunidade de descendentes de escravos. 2006. 116 f. Dissertação (Mestrado Profissional em Bens Culturais e Projetos Sociais)Fundação Getúlio Vargas, Rio de Janeiro, 2006.

MOTA, E. A. O olhar dos agentes escolares sobre a lei 10.639/03: o desafio de sua implementação. 2009. 149 f. Dissertação (Mestre em Políticas Sociais)-Universidade Estadual do Norte Fluminense Darcy Ribeiro, Campos dos Goytacazes, 2009.

MUNANGA, K. (Org.). Superando o racismo na escola. Brasília: MEC, 2005.

MUNANGA, K. Origens africanas do Brasil contemporâneo: história, línguas, culturas e civilizações. São Paulo: Globo, 2009.

PIRES, C. S. et al. Fazendas históricas. Itaperuna: Editora Damadá Artes Gráfica e Editora LITA, 2005.

RIBEIRO, D. O que é lugar de fala. Belo Horizonte: Letramento, 2017. (Coleção Feminismos Plurais).

SANTOS, S. A. A Lei no ${ }^{\circ}$ 10.639/03 como fruto da luta anti-racista do Movimento Negro. In: BRASIL. Ministério da Educação. Secretaria de Educação Continuada, Alfabetização e Diversidade. Educação anti-racista: caminhos abertos pela Lei Federal no 10.639/03. Brasília: MEC, Secretaria de Educação Continuada, Alfabetização e Diversidade, 2005. (Coleção Educação para todos).

SOUZA, M. A.; CUNHA JUNIOR, H. Bairros Negros e suas Formações na Cidade de Natividade-RJ. In: CUNHA JUNIOR, H. et al. (Org.). Bairros negros cidades negras. Fortaleza, CE: Editora Via Dourada, 2019.

SOUZA, M. L. Os conceitos fundamentais da pesquisa sócio-espacial. São Paulo: Bertrand Brasil, 2018. 
SOBRE OS AUTORES

Felício Alves de Azeredo - Azeredo, F. A. Mestrando em Geografia Universidade Federal Fluminense/Programa de Pós-Graduação em Geografia da UFF/CAMPOS. Grupo de pesquisa: NEPECGIM.

Marcia Aparecida Pereira de Mello. Profa. Escola Municipal Ary Parreiras Itaperuna - RJ. Mestrando em Geografia - Universidade Federal Fluminense/ Programa de Pós-Graduação em Geografia da UFF/CAMPOS. Grupo de pesquisa: NEPECGIM.

Edimilson Antônio Mota - Mota, E. A. Prof. da Licenciatura em Geografia e do PPG UFF Campos. Coordenador do Núcleo de Ensino e Pesquisa sobre Espaço e Currículo de Geografia e Imagem e Multiculturalismo - NEPECGIM. 